\title{
TPS-Based Interactive Multimedia to Improve Learning Effectiveness
}

\author{
Wildan Juliardi ${ }^{1}$, Rasim $^{2}$, Eka Fitrajaya Rahman ${ }^{3}$, Munir $^{4}$ \\ \{wildan.juliardi@student.upi.edu ${ }^{1}$,rasim@upi.edu², ekafitrajaya@upi.edu ${ }^{3}$, munir@upi.edu ${ }^{4}$ \} \\ Department of Computer Science Education Universitas Pendidikan Indonesia, Jl. Setiabudi No. 229 \\ Bandung Indonesia ${ }^{1,2,3,4}$
}

\begin{abstract}
Teacher-centered learning models make student activities limited. Though the effectiveness of learning can be seen from the activities of students in learning. For this reason, students need to be invited to think, discuss, and share with others. This research was conducted to test the Think-Pair-Share (TPS) model in the effectiveness of learning. This research uses the advantages of interactive multimedia that implements the model. This research uses a comprehensive life cycle method in multimedia development and quantitative methods in learning analysis data with experiment one-group pre-test and post-test. Research results can be seen from the student's response to multimedia is $87,87 \%$, in this case, means that multimedia is very helpful in student-centered activities and cognitive improvement with a gain value of 0.41 in the medium category.
\end{abstract}

Keywords: Interactive multimedia, Think pair share models, Learning Effectiveness

\section{Introduction}

Teacher-centered learning limits student activity. Though the effectiveness of learning is determined by the activeness of students in learning. Student activity can be improved if learning is student-centered through discussion.

On the other hand, information and communication technology has been widely used in supporting learning. One of them is interactive multimedia which provides teaching materials in various ways [1]. Previous research has proven the role of interactive multimedia in enhancing learning [2], make learning effective [3-6], improve attitude and quality of learning [7].

The effectiveness of learning is also determined by the interaction of students with other students during the learning process. Cooperative learning methods are the solution. The TPS model is a type of cooperative learning that is designed to influence student interaction patterns in working together to help each other in a small group. This model has helped improve students' collaborative skills [8], improve student cognitive [9],[10], increase motivation [9], and increase engagement in learning [11].

The use of TPS and interactive multimedia provides has increased learning achievement in mathematics. This research intends to investigate the implementation of TPS-based interactive multimedia in network administration learning in SMK majoring in Computer and Network Engineering [12]. 


\section{Research Method}

The respondents of this study were students of class XI of Network Computer Engineering at the Vocational High School 'PU' Bandung. The research design used in this study is the experiment one-group pre-test and post-test design as in Table 1.

Table 1. One-group pretest-posttest.

\begin{tabular}{|c|c|c|c|c|}
\hline Media & Group & Pre-test & Treat & Post-test \\
\hline $\begin{array}{l}\text { TPS-based } \\
\text { Interactive } \\
\text { Multimedia }\end{array}$ & $\begin{array}{l}\text { Upper } \\
\text { Middle } \\
\text { Lower }\end{array}$ & $\mathrm{O}_{1}$ & $X$ & $\mathrm{O}_{2}$ \\
\hline
\end{tabular}

The pre-test is done before students are given to know the initial ability, while Post-test is done after students receive learning. Testing is done by using the $\mathrm{N}$-Gain test where there are several categories, namely: upper group, middle group, and lower group.

Whereas interactive multimedia development is carried out in stages: analysis, design, development, implementation, and assessment. In the analysis stage, data is collected in two ways, namely through literature studies and interviews. A literature study is done by studying the TPS learning model or interactive multimedia. While interviews were conducted with teachers and students at the "PU" Vocational High School to find out the current learning conditions. The data obtained is useful for determining subjects and multimedia features to be built.

Next is the design stage. Data collected at the analysis stage will be used to design the software to be developed. In this stage, there are several elements including the content of teaching materials, evaluation questions, flowcharts and designing storyboards for development purposes.

After the researchers carry out the design phase, the next stage is development. At this stage, the researchers began to create a user interface, by implementing each phase of the TPS model in stages on multimedia, and testing with the black box technique. After making sure that the product is free from errors by researchers, the product will then go through an expert validation phase carried out by expert judgment or ask a number of experts in their fields to assess the multimedia products that have been made.

The implementation phase is carried out to implement interactive multimedia in learning. This implementation was carried out on 36 students. Starting with a pre-test as many as 25 Questions about routing material, static routing, dynamic routing, and NAT, then giving material at least three meetings and ending with a post-test of 25 questions.

The assessment stage is done by processing the data of the results of the pretest and posttest that have been done by students to prove whether there is an increase in learning outcomes by applying interactive multimedia TPS models using the N-Gain Test. Assessment is also carried out by processing data on student responses to media after learning using multimedia instruments through the rubric of mania - students. 


\section{Result and Discussion}

After the multimedia is revised and declared feasible, the next step is to implement multimedia to students. Testing is conducted on students of class XI Vocational High School "PU" Bandung. The test was carried out 3 times because there were 3 main materials, the firstclass learning was for pre-test and providing routing and static routing material, the second class learning was for dynamic routing material and the last ones were for NAT material presentation and post-test. To determine the impact of implementing TPS-based interactive multimedia, an assessment was conducted in the form of pre-test and post-test. The pre-test is done before learning to determine the initial abilities of students. Post-test is done after learning to find out the learning outcome.

The interactive multimedia interface can be seen in Figure 1 to Figure 6. Figure 1 shows the opening page of learning with network administration material. On this page, there is the display of a study room and a trophy as a background image. This picture is intended to foster student motivation. There are 3 menus provided, namely: 'start to learning', 'quizzes', and 'information about the system'.

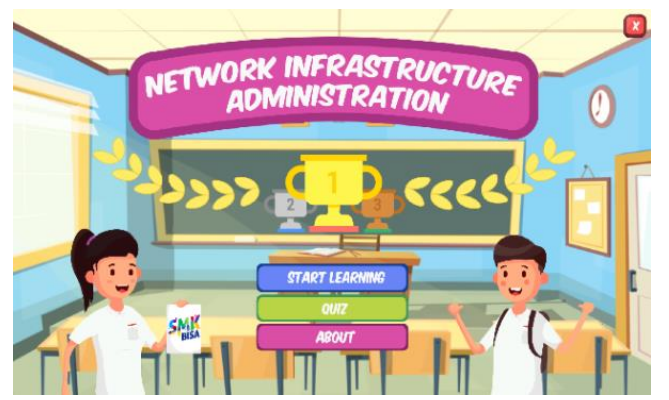

Fig. 1. The interface of the opening page.

Figure 2 will appear if you select the 'start to learn' menu in Figure 1. The teaching material provided is related to routing with the sub-topics introductory routing, static routing, dynamic routing, and addressing in the network.

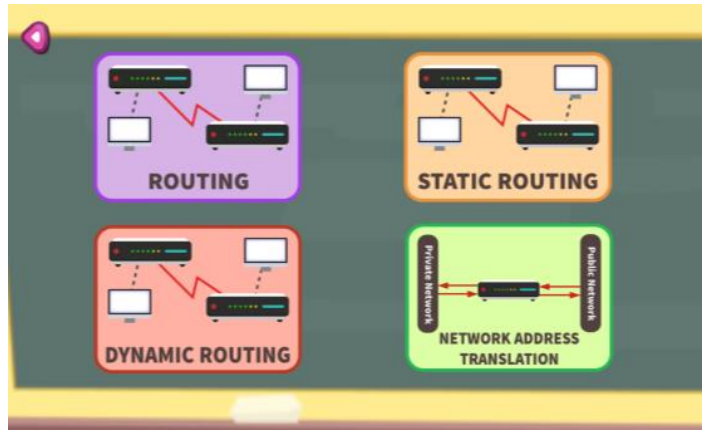

Fig. 2. The interface of Material Selection. 
This selection material menu can be freely chosen by students. Mastery learning is attained if students have learned all the material provided. If one of the menus is selected, then Figure 3 will appear containing the teaching material. in the case, Figure $\mathbf{3}$ shows material detail if the Routing menu selected. This teaching material can be displayed in the form of presentation slides or learning videos. Figure 3 is an example of teaching material in the form of video tutorials, animation and simulation videos and others. Figure $\mathbf{4}$ is an example of teaching the material in the form of an image showing by the slide presentation.

The interface of learning in Figure 3 and Figure 4 represent the stages of Think in the TPS model. At this stage, student learns the material individually.

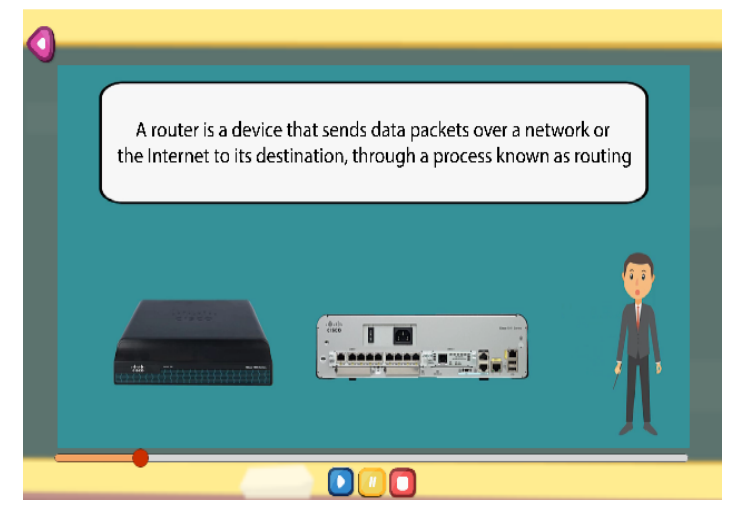

Fig. 3. Interface of Material in the form of video.

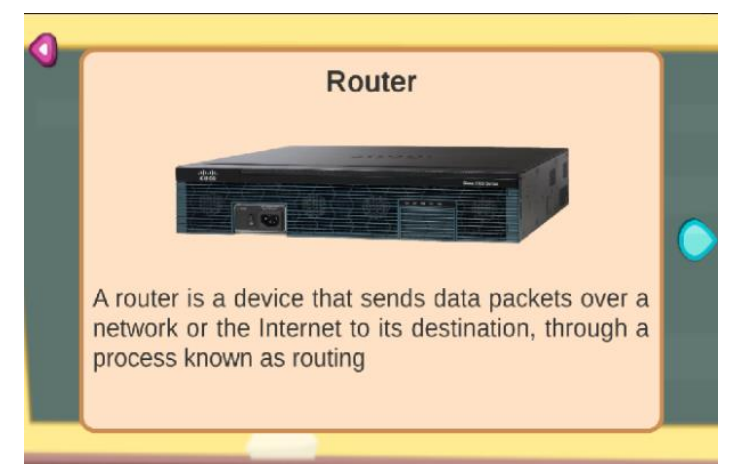

Fig. 4. The interface of Material in the form of the slide presentation.

The pair stage is a discussion between two students in the small group. Discussion is carried out to solve problems in the form of solving quiz questions. The display of problemsolving can be seen in Figure 5 and Figure 6. A pair discussion is held with each student giving their respective answers to the given problem then a discussion of the answers by the two students.

The Share Stages are done by sending or presenting the results of paired discussions to all students. 
Table 2. Media Judgment Results.

\begin{tabular}{|c|c|c|c|c|c|c|c|c|c|c|}
\hline \multirow[t]{3}{*}{ No } & \multicolumn{10}{|c|}{ Aspect } \\
\hline & \multicolumn{2}{|c|}{ Mechanism } & \multicolumn{2}{|c|}{$\begin{array}{l}\text { Multimedia } \\
\text { Element }\end{array}$} & \multicolumn{2}{|c|}{$\begin{array}{l}\text { Information } \\
\text { Structure }\end{array}$} & \multicolumn{2}{|c|}{ Document } & \multicolumn{2}{|c|}{$\begin{array}{l}\text { Content } \\
\text { Quality }\end{array}$} \\
\hline & NA & $\mathrm{P}(\%)$ & NA & $\mathrm{P}(\%)$ & NA & $\mathrm{P}(\%)$ & NA & $\mathrm{P}(\%)$ & NA & $\begin{array}{l}\mathrm{P} \\
(\%)\end{array}$ \\
\hline 1 & 14,4 & 90 & 7.3 & 91,3 & 14 & 87,5 & 7,2 & 90 & 46,8 & 90 \\
\hline 2 & 15,5 & 96,9 & 7,5 & 93,8 & 13 & 81,3 & 7,5 & 93,8 & 51 & 98,1 \\
\hline Sum & 29,9 & 186,9 & 14,8 & 185 & 27 & 168,8 & 14,7 & 183,8 & 97,8 & 188,7 \\
\hline Ave & $\begin{array}{l}14,9 \\
5\end{array}$ & 93.43 & 7,4 & 92,5 & 13,5 & 84,4 & 7,4 & 91,9 & 48,9 & 94,4 \\
\hline
\end{tabular}

Before knowing whether there is an influence of learning multimedia on student learning outcomes, the prerequisite test is carried out to determine whether the research data processing will use a parametric or non-parametric test.

The normality test using the Shapiro-Wilk method with significance alpha 0.05 aims to determine whether the data is normally distributed or not. Based on the calculation results, it is found that the significant level of pre-test data is $0.054>0.05$ and the post-test is $0.067>0.05$, so it can be concluded that the distribution of the two data is normally distributed.

The homogeneity test uses the Levene method to find out whether the variances of the pre-test and post-test are the same. Based on the homogeneity test results found that the significance of the pre-test and post-test is $0.088>0.05$, so it can be concluded that the pretest and post-test data have the same variance (homogeneous).

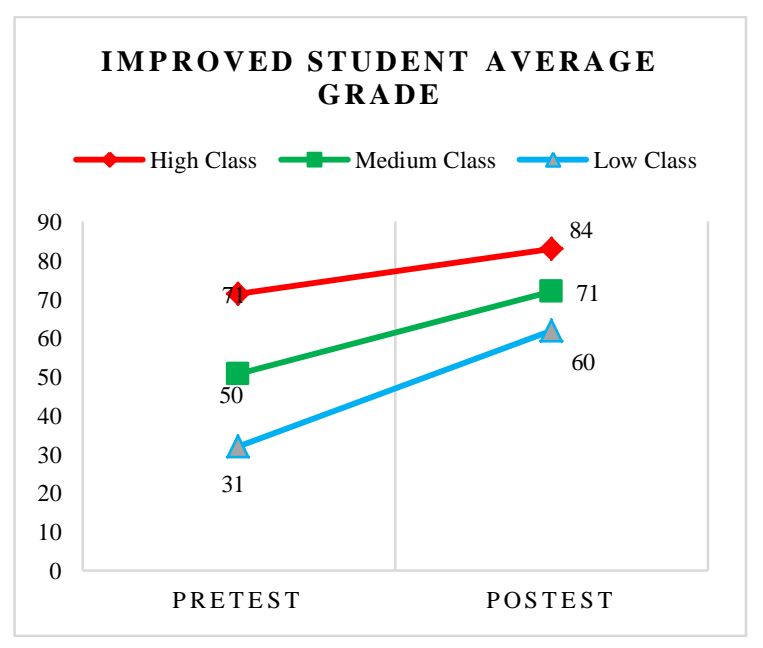

Fig. 5. Improved Student Grades Chart.

Testing of learning achievements is done in two ways, namely: 1) test the average value of pre-test and post-test, 2) gain test. Test the average value can be seen in Figure 7. Based on Figure 7 the results of an increase in the average value of the upper-class group from 71 (pre- 
test) to 84 (post-test), in the middle class the average value of 50 (pre-test) to 71 (post-test) and in the lower class the average value of 31 (pre-test) to 60 (post-test).

To determine the effectiveness of the application of multimedia to learning outcomes using the N-Gain test. Based on the calculation, the results obtained in the upper group get the gain average of 0.42 with the category "Medium", in the middle class the average gain is 0.41 with the category "Medium" and in the lower class get a mean gain of 0.41 with the category " Medium ". It can be concluded that the effectiveness of the use of interactive multimedia TPS models in network infrastructure administration subjects get an average gain of 0.41 in the "Medium" category. These results can be seen in table 3.

Table 3. Obtaining N-Gain for Each Group.

\begin{tabular}{llllll}
\hline Group & Information & Pre-test & Post-test & Gain & Criteria \\
\hline Upper & Max & 76 & 88 & 0,50 & Medium \\
& Min & 68 & 80 & 0,38 & Medium \\
& Average & 71 & 84 & 0,42 & Medium \\
& The amount of data & 6 & & & \\
Middle & Max & 56 & 80 & 0,45 & Medium \\
& Min & 40 & 64 & 0,31 & Medium \\
& Average & 50 & 71 & 0,41 & Medium \\
& The amount of data & 27 & & & \\
& Max & 32 & 64 & 0,41 & Medium \\
& Min & 28 & 60 & 0,41 & Medium \\
& Average & 31 & 60 & 0,41 & Medium \\
& The amount of data & 4 & & & \\
\hline
\end{tabular}

After knowing the effectiveness of multimedia in learning, the next test is knowing students' responses to multimedia using multimedia instruments mania - student rubric in which there are 5 aspects of the media being assessed namely mechanism, elements, information structure, documentation and quality of content. The test data can be seen in table 2. The table shows that the results of the average of all aspects in the upper-class group were $87.9 \%$ with the category of "very good", in the middle-class group the average of all aspects was $87.3 \%$ with the category of "very good" and in the lower class group, the average value of all aspects of the media was $88.4 \%$ with the category "very good". Based on these values shows that TPS-based interactive multimedia can be used for learning. Furthermore, the use of multimedia is expected to have a positive effect on the progress of education in Indonesia.

\section{Conclusion}

Based on the research results of Interactive Multimedia Development based on Think Pair Share Model shows the improvement of Student Learning Outcomes in Network Infrastructure Administration Subjects conducted to XI students majoring in Computer Engineering and Network Vocational High School "PU" Bandung. But the Gain value obtained is still in the 
medium category, this opens the gap for follow-up research by personalizing learning. The determination of students' models becomes very important for follow-up learning [13].

\section{References}

[1] Siagian, S.: Development of Interactive Multimedia Learning in Learning Instructional Design. Journal of Education and Practice, Vol. 5, No. 32, pp. 44-51 (2014)

[2] Rajendra, I. M., and Sudana, I. M.: The Influence of Interactive Multimedia Technology to Enhance Achievement Students on Practice Skills in Mechanical Technology. In The 2nd International Joint Conference on Science and Technology (IJCST). (2017)

[3] Zhang, D.: Interactive Multimedia-Based E-Learning: A Study of. The American Journal of Distance Education, Vol. 19, No. 3, pp. 149-162 (2005)

[4] Tambunan, H., and Napitupulu, E.: Effectiveness of Interactive Multimedia Based Learning Model in Engineering Mechanics. International Education Studies, Vol. 9, No. 10, pp. 155-162 (2016)

[5] Oyeyemi, F., and Daniel, U.: The Effects of Interactive Multimedia on English Language Pronunciation Performance of Pulils in the Nigerian Primary Schools. Research on Humanities Nad Sicial Sciences, Vol. 6, No. 9, pp. 71-78 (2016)

[6] Masran, S. H., Marian, M. F., Amin, F., Yunus, N., Rahim, M. B., and Baser, J. A.: Effectiveness of Using an Interactive Media in Teaching and Learning: A Case Study. In IEEE 9th International Conference on Engineering Education (ICEED) (pp. 222-227) (2017)

[7] Leow, M. F.: Interactive Multimedia Learning: Innovating Classroom Education in a Malayasian University. The Turkish Online Journal Od Educational Technology, Vol. 13, No. 2, pp. 99-110 (2014)

[8] Sumekto, D. R.: Investigating the Influence of Think-Pair-Share Approach Toward Students' Reading Achievement. Lingua Cultura, Vol. 12, pp. 195-202 (2018)

[9] Hetika, Farida, I., and Sari, Y. P.: Think Pair Share (TPS) as Method to Improve Student's Learning Motivation and Learning Achievement. Dinamika Pendidikan, Vol. 12, No. 9, pp. 125-135 (2017)

[10] Bamiro, A. O.: Effects of Guided Discovery and Think-Pair-Share Strategies on Secondary School Students' Achievement in Chemistry. (2015)

[11] Kothiyal, A.: Effect of Think-Pair-Share in a large CS1 class: $83 \%$ sustained engagement. (2010)

[12] Rochmad, and Sugiharti, E.: TPS Application Based on Mouse Mischief for Improving the Ability to Solve Mathematics Problem for Senior High School Students in Temanggung Indonesia. International Journal of Education and Research, Vol. 3, No. 3, pp. 331-338. (2015)

[13] Rasim, Rosmansyah, Y., Langi, A. Z. R., and Munir.: Selection of Learning Materials Based on Students Behaviors in 3DMUVLE. TELKOMNIKA, Vol. 16, No. 5, pp. 2127-2136 (2018) 